\title{
The effect of chemotherapy on expression of folate receptor-alpha in ovarian cancer
}

\author{
Lucia M. A. Crane • Henriette J. G. Arts • Marleen van Oosten • Philip S. Low • \\ Ate G. J. van der Zee • Gooitzen M. van Dam • Joost Bart
}

Accepted: 22 May 2011 / Published online: 7 June 2011

(C) The Author(s) 2011. This article is published with open access at Springerlink.com

\begin{abstract}
Background Folate receptor alpha (FR- $\alpha)$ has been identified as a potential target in ovarian cancer for diagnostic and therapeutic purposes, based on its overexpression in serous epithelial ovarian carcinoma. The effect of chemotherapy on FR- $\alpha$ expression may be important in the applicability of FR- $\alpha$ directed agents in the case of residual tumor tissue. The objective of this study was to assess FR- $\alpha$ expression in ovarian carcinoma and to evaluate whether FR- $\alpha$ expression is altered by chemotherapy.

Materials \& methods FR- $\alpha$ expression was analyzed by semi-quantitative scoring of immunohistochemical staining on tissue microarrays (TMAs) from a database containing 361 ovarian cancer tissue samples, of which 210 serous and 116 non-serous carcinoma (35 missing). Serous carcinoma samples included 28 matched samples with tissue from both primary surgery and interval debulking surgery, and 12
\end{abstract}

L. M. A. Crane · M. van Oosten · G. M. van Dam

Department of Surgery, Division of Surgical Oncology,

University Medical Center Groningen,

Groningen, the Netherlands

\section{H. J. G. Arts · A. G. J. van der Zee}

Department of Obstetrics and Gynaecology, Division of Gynaecologic

Oncology, University Medical Center Groningen,

Groningen, the Netherlands

\section{P. S. Low}

Department of Chemistry, Purdue University,

West Lafayette, IN 47907, USA

J. Bart ( $\square)$

Department of Pathology and Medical Biology,

University Medical Center Groningen,

P.O. Box 30.001,

9700 RB Groningen, the Netherlands

e-mail: j.bart@path.umcg.nl matched samples with tissue from both primary surgery and surgery for recurrent disease.

Results FR- $\alpha$ expression was seen in $81.8 \%$ of serous ovarian cancers versus $39.9 \%$ of non-serous carcinomas $(p<0.001)$. In matched serous carcinoma samples, no significant change in FR- $\alpha$ expression in vital tumor tissue after chemotherapy was observed $(p=0.1)$. FR- $\alpha$ expression was not a prognostic marker of progression free survival $(p=0.8)$ or overall survival $(p=0.7)$.

Conclusion FR- $\alpha$ was expressed in the majority of serous ovarian tumors, although $>50 \%$ of cases showed only weak expression. Chemotherapy did not alter expression rates in remaining vital tumor tissue, indicating that folate-targeted agents may have a place in the treatment for ovarian cancer, before as well as after chemotherapy. Furthermore, FR- $\alpha$ status did not influence survival.

Keywords Folate receptor-alpha - Ovarian cancer. Immunohistochemistry

$\begin{array}{ll}\text { Abbreviations } \\ \text { FR- } \alpha & \text { Folate receptor-alpha } \\ \text { OS } & \text { Overall survival } \\ \text { PFS } & \text { Progression free survival }\end{array}$

\section{Introduction}

Ovarian cancer is the leading cause of death among gynaecologic malignancies in the western world [7]. Because of late onset of symptoms, $75 \%$ of the patients are diagnosed with advanced disease. Prognosis in stage III and IV remains poor with 5-year survival rates of around $30 \%$ [18]. Novel approaches to improve survival include 
the development of tumor-targeted diagnostic agents and drugs. In ovarian cancer, the folate receptor alpha (FR- $\alpha)$ seems promising for tumor-targeting, as overexpression of FR- $\alpha$ is seen in $72-97 \%$ of serous epithelial ovarian tumors $[8,12,14]$.

Folic acid is used for synthesis of nucleotide bases and is under physiological conditions taken up by cells by the reduced folate carrier (RFC) [1]. A second mode by which folic acid can be internalized, is via the highaffinity folate receptor (FR), of which the alpha isoform is overexpressed in $\sim 40 \%$ of solid tumors, including ovarian, renal, lung and breast cancers [14]. Uptake of folate and folate-conjugates occurs via receptor-mediated endocytosis [9]. Since the macromolecule inside the endosome remains intact, it can fully exert its function inside the cell $[9,11]$. After endocytosis, the FR is recycled back to the cell surface where it can again bind circulating folate. The high affinity of folate for the FR combined with the rapid recycling of the receptor makes this receptor an attractive factor for targeted diagnostics and therapy. In the last decade, several FR-targeted substances have been developed. SPECTscanning using the radionuclide ${ }^{111}$ In-DTPA-folate showed a strong signal originating from ovarian tumors, as well as from the kidneys, but no uptake in benign tumors $[13,15]$. Subsequently, interest shifted towards a ${ }^{99 \mathrm{~m}}$ Tc-based folate-tracer because of its shorter half-life and lower production costs [10]. FR- $\alpha$ targeted chemotherapy with farletuzumab (MORAb-003), an antibody with high affinity for FR- $\alpha$, is currently under investigation in the first clinical trials $[2,6,16]$. Furthermore, a clinical trial is being carried out evaluating the combination of EC145, an FR- $\alpha$ targeted drug, with Doxil, compared with Doxil alone for platinum resistant ovarian cancer (PRECEDENT study; identifier no. NCT00722592; www.clinicaltrials.gov).

The possibilities for FR-targeted diagnostics and therapeutics seem promising, but applicability depends entirely on FR-expression by the target tissue. Chemotherapy, either (neo)adjuvant or intraperitoneal, is a vital part in the treatment for ovarian cancer. Therefore, the relevance of FR- $\alpha$ targeted agents depends on whether chemotherapy influences FR- $\alpha$ expression on remaining vital tumor tissue. Previous studies show that FR- $\alpha$ is overexpressed on the majority of primary ovarian tumors, however, the effect of chemotherapy has only been described once, reporting no significant change in FR- $\alpha$ expression [8]. To address this question in more detail, we analyzed FR- $\alpha$ expression in ovarian cancer tumor samples obtained at primary surgery as well as in samples obtained directly post-chemotherapy at interval debulking surgery, and in samples from surgery for recurrent disease. In addition, we evaluated the impact of FR- $\alpha$ expression on survival.

\section{Materials \& methods}

\subsection{Patient tissue samples}

Ovarian cancer specimens were collected from the databank of the University Medical Center Groningen (UMCG). Since 1985 all clinicopathological and followup data of epithelial ovarian cancer patients treated at the UMCG are prospectively stored in a database. Tumor samples from 361 patients were assembled on a tissue microarray. Borderline and non-epithelial malignancies were excluded. Treatment for all patients consisted of

Table 1 Patient characteristics

\begin{tabular}{|c|c|c|c|}
\hline \multirow[b]{2}{*}{ Age (mean, min-max, SD) } & \multicolumn{3}{|c|}{ All tumors $(n=361)$} \\
\hline & 57.5 & $16-89$ & SD 13.2 \\
\hline Age; grouped & $n$ & $\%$ & \\
\hline$<58$ years old & 168 & 46.5 & \\
\hline$\geq 58$ years old & 192 & 53.2 & \\
\hline Missing & 1 & 0.3 & \\
\hline Tumor type & $n$ & $\%$ & \\
\hline Serous adenocarcinoma & 210 & 64.4 & \\
\hline Other & 116 & 35.6 & \\
\hline - Mucinous adenocarcinoma & 40 & 12.3 & \\
\hline - Endometrioid adenocarcinoma & 51 & 15.6 & \\
\hline - Clear cell carcinoma & 22 & 6.8 & \\
\hline - Undifferentiated & 3 & 0.9 & \\
\hline Missing & 35 & & \\
\hline FIGO-stage & $n$ & $\%$ & \\
\hline Stage I & 70 & 19.4 & \\
\hline Stage II & 30 & 8.3 & \\
\hline Stage III & 205 & 56.8 & \\
\hline Stage IV & 54 & 15.0 & \\
\hline Missing & 2 & 0.6 & \\
\hline Grade & $n$ & $\%$ & \\
\hline Grade I & 57 & 15.8 & \\
\hline Grade II & 96 & 26.6 & \\
\hline Grade III & 160 & 44.3 & \\
\hline Undifferentiated & 15 & 4.2 & \\
\hline Missing & 33 & 9.1 & \\
\hline Rest tumor after primary surgery & $n$ & $\%$ & \\
\hline Yes & 224 & 62.0 & \\
\hline No & 125 & 34.6 & \\
\hline Missing & 12 & 3.3 & \\
\hline Size of rest tumor & $n$ & $\%$ & \\
\hline$<2 \mathrm{~cm}$ & 168 & 46.5 & \\
\hline$\geq 2 \mathrm{~cm}$ & 163 & 45.2 & \\
\hline Missing & 30 & 8.3 & \\
\hline Progression free survival (months) & & & \\
\hline (mean, min-max, SD) & 29.6 & $0-207$ & SD 36.3 \\
\hline
\end{tabular}


surgery followed by adjuvant chemotherapy (platinumbased regimens; since 1995 supplemented by taxanes). Staging was performed surgically, according to the FIGO (International Federation of Gynaecology and Obstetrics) classification [4]. All patient data were anonymized and all studies concerning this databank were conducted in accordance with the Declaration of Helsinki principles and with the rules and regulations posed by the medical ethical research board (IRB) of the UMCG.

\subsection{Sample preparation and immunohistochemistry}

For previous studies, tissue microarrays (TMAs) were constructed of tumors from 361 patients (de Graeff et al., 2006 [5]), of which 28 matched cases for both primary and interval debulking surgery, and 12 matched cases for primary surgery and surgery for recurrent disease. The TMAs contained control cores consisting of normal ovarian and endometrial tissue. In order to determine whether these TMAs were suitable for quantification of FR- $\alpha$ expression, it was necessary to evaluate the homogeneity of the FR- $\alpha$ staining. For this purpose, ten randomly selected ovarian tumor samples were stained for FR- $\alpha$ following the immunohistochemical procedure described below. Uniform staining was observed throughout tumor tissue in these samples, indicating the feasibility of using TMAs for further analyses. Renal tissue, on which FR- $\alpha$ is present under physiologic conditions, was synchronously stained as positive control.

TMAs were cut into $3 \mu \mathrm{m}$ sections and fixed on coated glass slides. Sections were deparaffinized with xylene, rehydrated through a graded series of ethanol and rinsed well in distilled water. Antigen retrieval was achieved by heating in a high pressure cooker (Pascal, Dako) in a Target Retrieval Solution (Dako) for $1 \mathrm{~min}$ at $125^{\circ} \mathrm{C}$ and cooled down to $90^{\circ} \mathrm{C}$ without venting of pressure. Slides were cooled down to room temperature and rinsed with phosphate buffered saline (PBS). After blocking endogenous peroxidase in $0.3 \% \mathrm{H}_{2} \mathrm{O}_{2}$ in PBS for $30 \mathrm{~min}$, sections were incubated with the monoclonal antibody mAB343 $(1.8 \mathrm{mg} / \mathrm{ml}$; a generous gift from prof. P.S. Low, Endocyte Inc.) in a 1:500 dilution in 1\% BSA/PBS solution for $3 \mathrm{~h}$ at room temperature. After washing with PBS, the sections were incubated with mouse MACH3 (Biocare Medical). Peroxidase activity was visualized with 3,3-diaminobenzidine and slides were counterstained with haematoxylin, mounted with mounting medium and coverslipped.

\subsection{External validation}

In order to validate the staining technique, one TMA (55 samples; 4 cores each) was stained in the laboratory of P.S. Low. The similar results indicate validity of the staining protocol.

\subsection{Histological analysis}

TMAs were graded for FR- $\alpha$ staining using the following criteria: $\mathrm{x}=$ no tumor cells in TMA core or missing core; $0=$ no staining; 1 = weak staining; 2 = moderate staining; 3 = strong staining according to a previously published study [3]. A sample was considered positive when at least $25 \%$ of the
Fig. 1 FR- $\alpha$ expression in representative samples a-no expression (0); b-weak expression (1); $\mathbf{c}$ - moderate expression (2); d-strong expression (3)
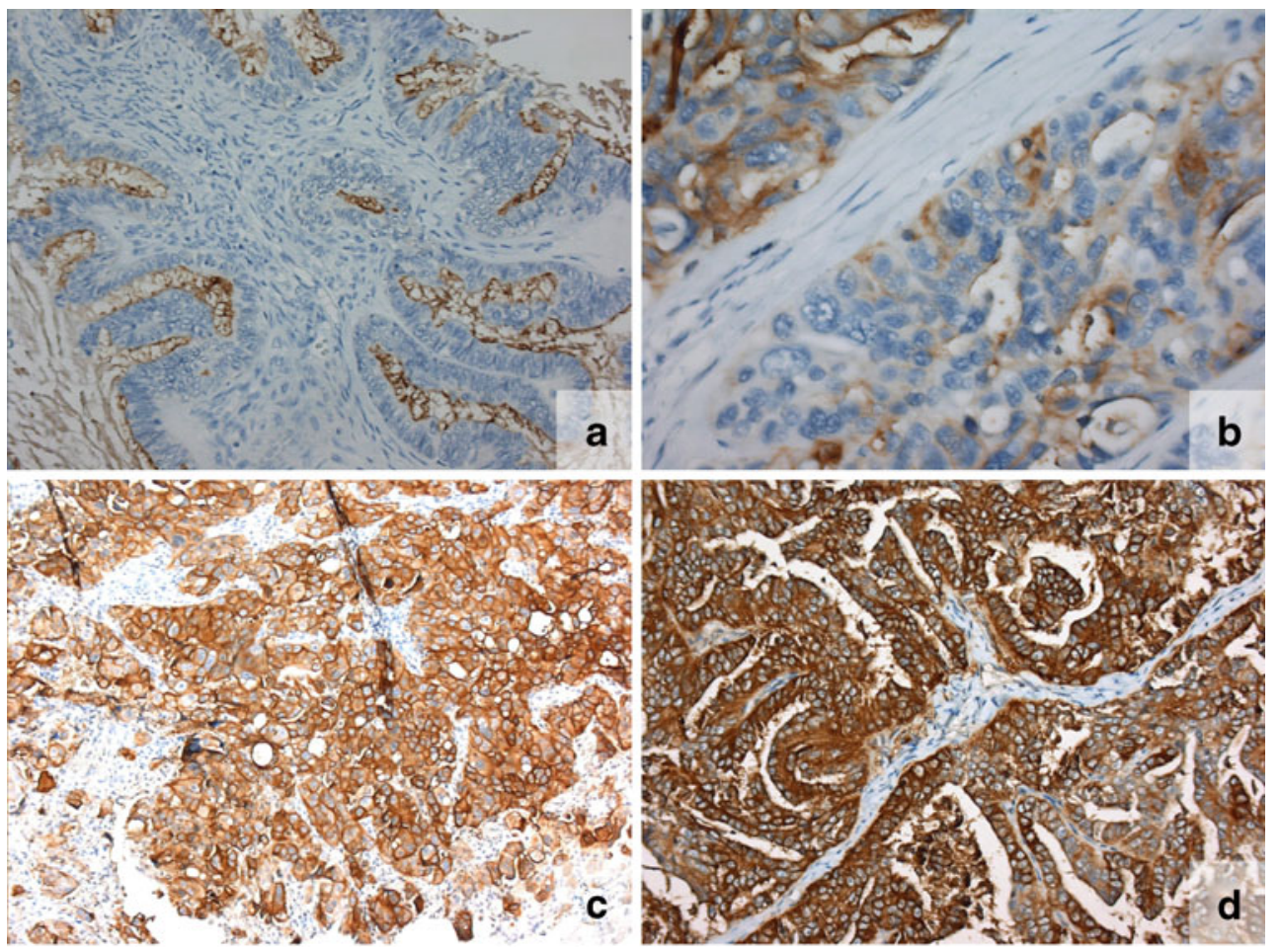
Table 2 FR- $\alpha$ expression subdivided into histology (top 3 rows, complete cohort; middle 3 rows, serous carcinoma; bottom 3 rows, non-serous carcinoma). Each group is subdivided into samples obtained at primary surgery, at interval debulking surgery or at surgery for recurrent disease. Expression scores are depicted as percentages

\begin{tabular}{lcccr}
\hline & Negative $(0)$ & Weak $(1)$ & Moderate $(2)$ & Strong (3) \\
\hline All primary $(n=216)$ & 28.2 & 47.2 & 19.9 & 4.7 \\
All interval $(n=39)$ & 10.3 & 43.5 & 38.5 & 7.7 \\
All recurrent $(n=23)$ & 26.1 & 34.8 & 21.7 & 17.4 \\
Serous primary $(n=165)$ & 18.2 & 53.3 & 23.0 & 5.5 \\
Serous interval $(n=38)$ & 7.9 & 44.7 & 39.5 & 7.9 \\
Serous recurrent $(n=16)$ & 18.8 & 43.8 & 25.0 & 12.5 \\
Other primary $(n=51)$ & 60.8 & 27.5 & 9.8 & 2.0 \\
Other interval $(n=1)$ & 100.0 & 0.0 & 0.0 & 0.0 \\
Other recurrent $(n=7)$ & 42.9 & 14.3 & 14.3 & 28.6 \\
\hline
\end{tabular}

tumor cells showed staining. All samples with $<2$ representative cores were excluded. First, all cores were judged separately. Second, one mean score was appointed to each sample, consisting of four cores. This score was based on the most frequent staining intensity observed in the sample. For additional analyses, cases were subdivided in a 'low staining' group (score 0 or 1) and in a 'high staining' group (score 2 or 3). Scoring was performed, after training, by the primary researcher (LMAC) and by the pathologist (JB). In case of different grading, the cores were discussed in a general meeting until consensus was met.

\subsection{Statistical analysis}

Descriptive statistics were calculated for variables of interest. Histology type and FR- $\alpha$ expression were compared using the chi-square test. Matched samples were compared using the Wilcoxon signed-rank test. For survival analyses, progression free survival (PFS) was defined as the time from primary surgery until progression of the disease or last follow-up. Disease-specific overall survival (OS) was defined as time from diagnosis until the last follow-up alive or death due to ovarian cancer. Survival curves were generated using KaplanMeier analysis. FR- $\alpha$ expression was tested as a prognostic factor according to a Cox proportional hazards model. All statistical analyses were carried out using the SPSS 16.0 software package for Windows (SPSS Inc., Chicago, USA). For all tests, p-values $<0.05$ were considered statistically significant.

\subsection{Digital microphotography}

Microphotographs shown in this paper were acquired using a Leica DM400B microscope and a Leica DFC320 digital camera (Leica Microsystems $\mathrm{GmbH}$, Wetzlar Germany).

Table 3 FR- $\alpha$ expression in primary tumor samples subdivided into histologic subtype. Non-serous carcinomas are further subdivided; shown in italic

\begin{tabular}{|c|c|c|c|c|c|c|}
\hline Tumor type & $\mathrm{N}$ & FR- $\alpha-$ & FR- $\alpha+$ & Weak (1) & Moderate (2) & Strong (3) \\
\hline \multirow[t]{2}{*}{ Serous $^{\mathrm{a}}$} & \multirow[t]{2}{*}{165} & 30 & 135 & 88 & 38 & 9 \\
\hline & & $18.2 \%$ & $81.8 \%$ & $53.3 \%$ & $23 \%$ & $5.5 \%$ \\
\hline \multirow[t]{2}{*}{ All other ${ }^{\mathrm{a}}$} & \multirow[t]{2}{*}{51} & 31 & 20 & 14 & 5 & 1 \\
\hline & & $60.8 \%$ & $39.2 \%$ & $27.5 \%$ & $9.8 \%$ & $2.0 \%$ \\
\hline \multirow[t]{2}{*}{ Mucinous } & \multirow[t]{2}{*}{11} & 5 & 6 & 4 & 2 & 0 \\
\hline & & $45.5 \%$ & $54.5 \%$ & $36.4 \%$ & $18.2 \%$ & \\
\hline \multirow[t]{2}{*}{ Endometrioid } & \multirow[t]{2}{*}{32} & 25 & 7 & 4 & 3 & 0 \\
\hline & & $78.1 \%$ & $21.9 \%$ & $12.5 \%$ & $9.4 \%$ & \\
\hline \multirow[t]{2}{*}{ Clear-cell } & \multirow[t]{2}{*}{5} & 1 & 4 & 4 & 0 & 0 \\
\hline & & $20 \%$ & $80 \%$ & $80 \%$ & & \\
\hline \multirow[t]{2}{*}{ Undifferentiated } & \multirow[t]{2}{*}{3} & 0 & 3 & 2 & 0 & 1 \\
\hline & & & & $66.7 \%$ & & $33.3 \%$ \\
\hline Missing & 35 & & & & & \\
\hline
\end{tabular}

$\mathrm{N}$; number of cases per group

FR- $\alpha-$; the number and percentage of samples showing no FR- $\alpha$ expression (negative)

FR- $\alpha+$; the number and percentage of samples showing FR- $\alpha$ expression. These are further subdivided into weak (1), moderate (2) and strong (3) expression (right half of table)

${ }^{a}$ FR- $\alpha$ expression in serous compared to non-serous carcinomas: $p<0.001$ 


\section{Results}

\subsection{Patient characteristics}

Baseline characteristics of the 361 patients included in the database are presented in Table 1.
Of these 361 , histology was unknown in 35 cases. Of the remaining 326 patients, 386 tumor samples were available, of which 295 obtained during primary surgery, 63 during interval surgery and 28 during surgery for recurrent disease.

Of the 326 cases with known histology, 210 cases (64.4\%), were serous carcinomas and 116 cases (35.6\%)
Table 4 Patient characteristics of matched serous carcinoma samples
Primary \& Postchemo (middle column); cases containing tumor tissue from both primary surgery and interval debulking surgery $(n=28)$ Primary \& Recurrent (right column); cases containing tumor tissue from both primary surgery and from surgery for recurrent disease $(n=12)$

\begin{tabular}{|c|c|c|c|c|c|c|}
\hline \multirow[b]{2}{*}{ Age (mean, min-max, SD) } & \multicolumn{3}{|c|}{ Primary $\&$ postchemo $n=28$} & \multicolumn{3}{|c|}{ Primary \& recurrent $n=12$} \\
\hline & 55.1 & $31-74$ & SD 9.3 & 49.8 & $31-68$ & SD 12.1 \\
\hline Age; grouped & $n$ & $\%$ & & $n$ & $\%$ & \\
\hline$<58$ & 13 & 46.4 & & 8 & 66.7 & \\
\hline$\geq 58$ & 15 & 53.6 & & 4 & 33.3 & \\
\hline Missing & 0 & 0.0 & & 0 & 0.0 & \\
\hline FIGO & $\mathrm{n}$ & $\%$ & & $\mathrm{n}$ & $\%$ & \\
\hline Stage I & 0 & 0.0 & & 1 & 8.3 & \\
\hline Stage II & 1 & 3.6 & & 2 & 16.7 & \\
\hline Stage III & 22 & 78.6 & & 8 & 66.7 & \\
\hline Stage IV & 5 & 17.9 & & 1 & 8.3 & \\
\hline Grade & $n$ & $\%$ & & $n$ & $\%$ & \\
\hline Grade I & 3 & 10.7 & & 2 & 16.7 & \\
\hline Grade II & 4 & 14.3 & & 3 & 25.0 & \\
\hline Grade III & 15 & 53.6 & & 6 & 50.0 & \\
\hline Undifferentiated & 2 & 7.1 & & 0 & 0.0 & \\
\hline Missing & 4 & 14.3 & & 1 & 8.3 & \\
\hline Rest tumor after primary surgery & $n$ & $\%$ & & $n$ & $\%$ & \\
\hline Yes & 28 & 100.0 & & 4 & 33.3 & \\
\hline No & 0 & 0.0 & & 7 & 58.3 & \\
\hline Missing & 0 & 0.0 & & 1 & 8.3 & \\
\hline Size of rest tumor & $n$ & $\%$ & & $n$ & $\%$ & \\
\hline$<2 \mathrm{~cm}$ & 1 & 3.6 & & 7 & 58.3 & \\
\hline$\geq 2 \mathrm{~cm}$ & 25 & 89.3 & & 2 & 16.7 & \\
\hline Missing & 2 & 7.1 & & 3 & 25.0 & \\
\hline Chemotherapy & $n$ & $\%$ & & $n$ & $\%$ & \\
\hline No chemo & 0 & 0.0 & & 1 & 8.3 & \\
\hline Platinum based & 14 & 50.0 & & 8 & 66.7 & \\
\hline Platinum/Taxane & 13 & 46.4 & & 3 & 25.0 & \\
\hline Missing & 1 & 3.6 & & 0 & 0.0 & \\
\hline \multicolumn{7}{|l|}{$\begin{array}{l}\text { Progression free survival } \\
\text { (months) }\end{array}$} \\
\hline (mean, min-max, SD) & 14.7 & $0-115$ & SD 21.1 & 46.6 & $11-124$ & SD 36.3 \\
\hline \multicolumn{7}{|c|}{ FR-alpha expression (mean, median, SD) } \\
\hline Primary tumor & 1.29 & 1.0 & SD 0.897 & 1.17 & 1.0 & SD 1.03 \\
\hline Interval debulking & 1.54 & 2.0 & SD 0.838 & & & \\
\hline \multirow[t]{2}{*}{ Recurrent disease } & & & & 1.42 & 1.0 & SD 0.793 \\
\hline & & & $p=0.1$ & & & $p=0.5$ \\
\hline \multicolumn{7}{|c|}{ FR-alpha expression low/high (mean, median, SD) } \\
\hline Primary tumor & 0.36 & 0.0 & SD 0.488 & 0.4 & 0.0 & 0.515 \\
\hline Interval debulking & 0.52 & 1.0 & SD 0.509 & & & \\
\hline \multirow[t]{2}{*}{ Recurrent disease } & & & & 0.36 & 0.0 & 0.505 \\
\hline & & & $p=0.1$ & & & $p=1.000$ \\
\hline
\end{tabular}


were of all other histologic subtypes of which mucinous and endometroid adenocarcinoma were the most prevalent (12.3 and $15.6 \%$, respectively).

In the group of serous carcinomas, 28 matched cases contained tumor tissue from both primary and interval debulking surgery, and 12 cases contained tumor tissue from both primary and recurrent surgery. Only seven matched cases for primary and interval debulking surgery could be identified in the subgroup of non-serous carcinomas.

\subsection{FR- $\alpha$ expression}

Samples that contained less than two representative cores were excluded. Representative FR- $\alpha$ scores (Fig. 1) could
Fig. 2 FR- $\alpha$ expression pre- and post-chemotherapy. Left column: pre-chemotherapy.

Right column: post-

chemotherapy. a-negative/ negative. $\mathbf{b}-$ negative/ positive.

c-positive/negative.

d-positive/positive a

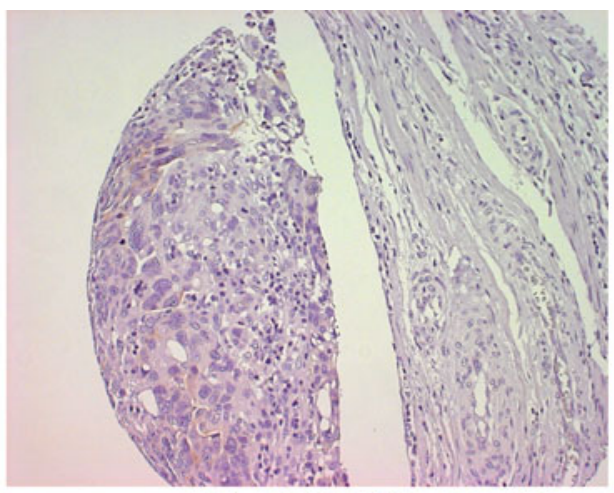

b
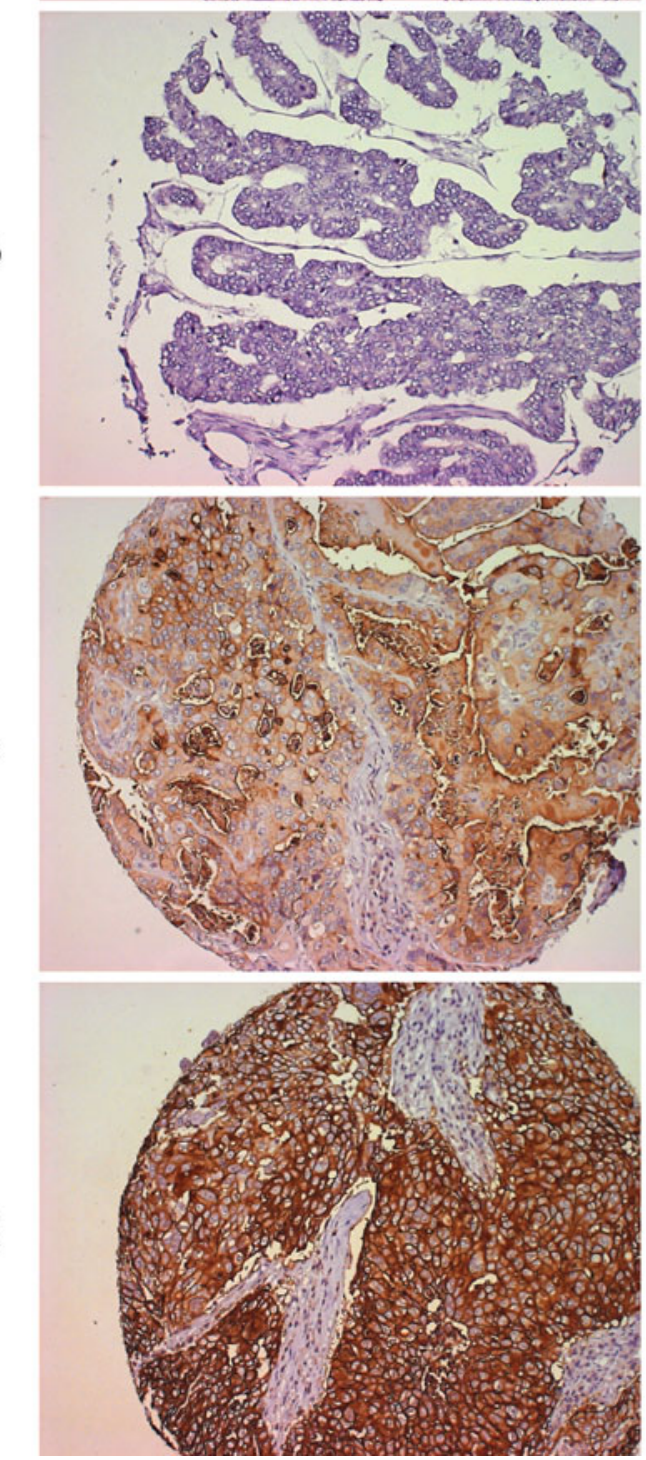
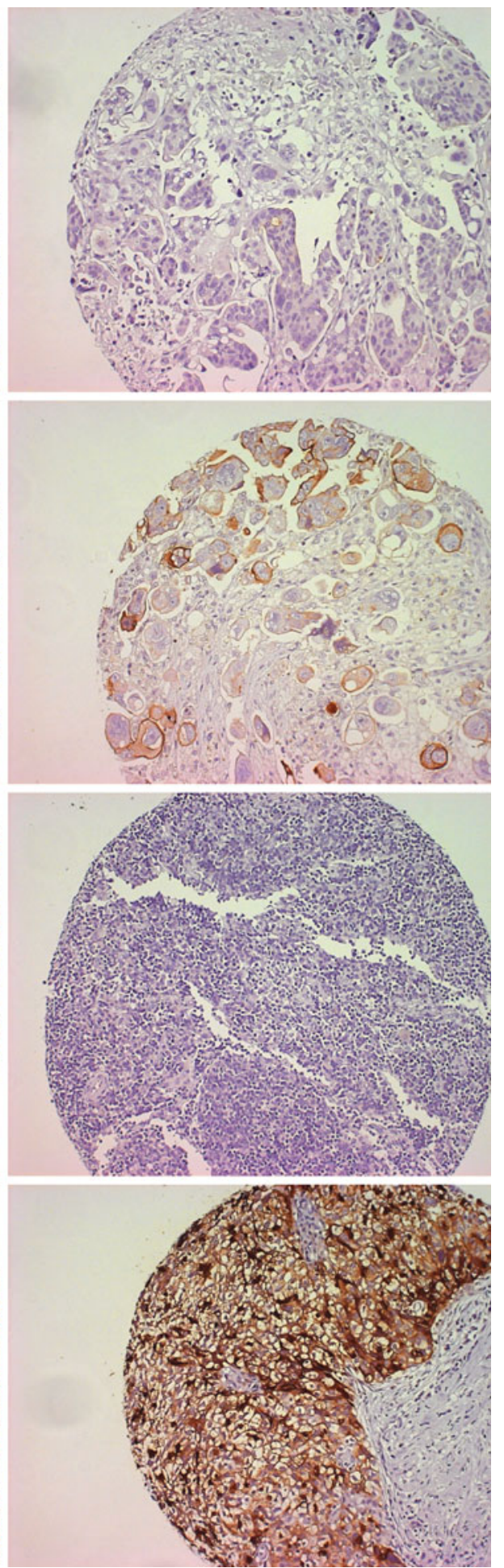
Table 5 Overall survival and progression free survival in univariate and multivariate analysis (Cox Regression Analysis)

\begin{tabular}{|c|c|c|c|c|c|c|c|c|c|c|c|c|}
\hline & \multicolumn{3}{|c|}{ Overall survival } & \multicolumn{3}{|c|}{ Progression free survival } & \multicolumn{3}{|c|}{ Overall survival } & \multicolumn{3}{|c|}{ Progression free survival } \\
\hline & \multicolumn{3}{|c|}{ Univariate } & \multicolumn{3}{|c|}{ Univariate } & \multicolumn{3}{|c|}{ Multivariate } & \multicolumn{3}{|c|}{ Multviariate } \\
\hline & HR & $95 \% \mathrm{CI}$ & $\mathrm{P}$ & HR & $95 \% \mathrm{CI}$ & $\mathrm{P}$ & HR & $95 \% \mathrm{CI}$ & $\mathrm{P}$ & HR & $95 \% \mathrm{CI}$ & $\mathrm{P}$ \\
\hline \multicolumn{13}{|c|}{ All patients with known histology $(N=326)$} \\
\hline Advanced stage & 8.1 & $4.7-14.1$ & $<0.001$ & 5.9 & $3.9-8.9$ & $<0.001$ & 4.6 & $1.8-12.2$ & 0.002 & 2.8 & $1.4-5.4$ & 0.003 \\
\hline Age $\geq 58$ years & 1.7 & $1.2-2.2$ & 0.001 & 1.5 & $1.1-1.9$ & 0.006 & 1.1 & $0.8-1.6$ & 0.5 & 1.0 & $0.7-1.4$ & 0.8 \\
\hline Serous type & 0.3 & $0.2-0.5$ & $<0.001$ & 0.3 & $0.2-0.4$ & $<0.001$ & 1.8 & $1.1-3.1$ & 0.03 & 2.0 & $1.2-3.4$ & 0.008 \\
\hline Residual disease $\geq 2 \mathrm{~cm}$ & 4.6 & $3.3-6.4$ & $<0.001$ & 4.6 & $3.4-6.4$ & $<0.001$ & 2.3 & $1.5-3.4$ & $<0.001$ & 2.4 & $1.6-3.6$ & $<0.001$ \\
\hline Grade III/undifferentiated & 2.8 & $2.0-3.9$ & $<0.001$ & 2.7 & $2.0-3.6$ & $<0.001$ & 0.7 & $0.5-1.1$ & 0.1 & 0.8 & $0.6-1.3$ & 0.008 \\
\hline FR- $\alpha$ overexpression & 1.2 & $0.8-1.7$ & 0.5 & 1.2 & $0.8-1.7$ & 0.3 & 0.8 & $0.5-1.1$ & 0.2 & 0.8 & $0.5-1.2$ & 0.2 \\
\hline
\end{tabular}

be obtained in 278 tumor samples (72\%), of which 216 from primary surgery, 39 from interval debulking surgery and 23 from surgery for recurrent disease. Of the 216 primary tumor samples, $71.8 \%$ showed FR- $\alpha$ expression and $28.2 \%$ was negative. Grade was not correlated to FR- $\alpha$ expression $(p=0.4)$.

An overview of FR- $\alpha$ expression subdivided into histology is shown in Tables 2 and 3. Of the primary serous carcinomas, $18.2 \%$ was negative; $53.3 \%$ showed weak staining, $23.0 \%$ moderate staining and $5.5 \%$ strong staining. Interval debulking tumor samples showed negative expression in $7.9 \%$, weak staining in $44.7 \%$, moderate staining in $39.5 \%$ and strong staining in $7.9 \%$. Recurrent tumors were negative in $18.8 \%$ while $43.8 \%$ showed weak staining, $25.0 \%$ moderate staining and $12.5 \%$ strong staining.

Primary non-serous carcinomas showed no staining in $60.8 \%$, weak staining in $27.5 \%$, moderate staining in $9.8 \%$ and strong staining in $2.0 \%$.

Using the chi square test, a significantly higher staining was observed in the primary serous carcinomas compared to non-serous carcinomas $(p<0.001)$.

The combined group of moderate and strong staining (scores 2-3) showed 28.5\% FR- $\alpha$ expression in serous primary tumors, versus $45.9 \%(p=0.04)$ of tumor samples at interval debulking and $33.3 \%$ of recurrent tumors $(p=1.000)$.

All positive controls, consisting of renal tissue, showed uniform FR- $\alpha$ staining, whereas no staining was observed on normal ovarian and endometrial tissue cores.

\subsection{FR- $\alpha$ expression pre- and postchemotherapy}

Twenty-eight cases within the group of serous carcinomas contained matched samples for both primary and interval debulking surgery. All patients had received either three or six cycles of chemotherapy, either platinum-based $(50.0 \%)$ or platinum/taxane $(46.4 \%)$. Nearly all patients had advanced disease (FIGO stage III-IV; 96.5\%). Characteristics of this subgroup of patients are shown in Table 4.
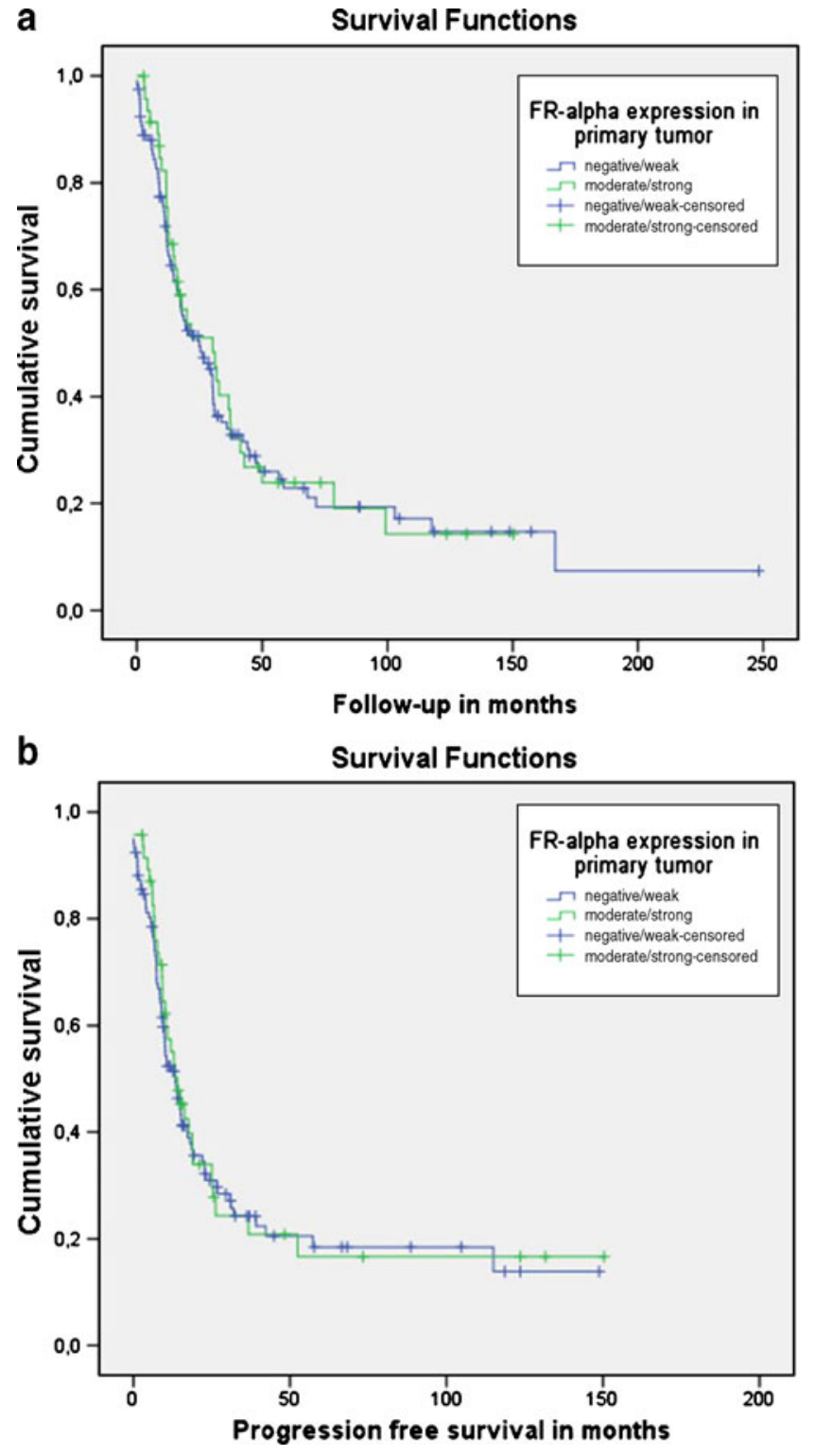

Fig. 3 Survival curves for serous tumors a-Overall survival (follow-up in months); $p=0.7 \mathbf{b}$-Progression free survival in months; $p=0.8$ 
Comparison of staining scores using the Wilcoxon Rank test showed no difference in FR- $\alpha$ expression $(p=0.1)$ in remaining vital tumor tissue. Similarly, no significant difference was found when comparing staining scores grouped into low expression (score 0 or 1 ) and high expression (score 2 or 3$)(p=0.1)$.

Twelve cases contained tissue from both primary and recurrent disease. All patients underwent three or six cycles of chemotherapy (Table 4). Comparison of staining scores showed no significant difference in FR- $\alpha$ expression $(p=0.5)$, nor in low versus high expression $(p=1.000)$. Staining patterns pre- and post-chemotherapy are shown in Fig. 2.

When combining scores from interval debulking surgery and surgery for recurrent disease, 37 cases are matched for primary and postchemotherapy scores (postchemotherapy either directly at interval debulking or at surgery for recurrent disease). Wilcoxon Rank test did not show a difference in FR- $\alpha$ expression between these groups ( $p=0.1$ ).

In the group of non-serous carcinomas, only one case was matched for primary and interval debulking surgery and four cases were matched for primary and recurrent disease. These numbers are considered too small to perform reliable statistical analyses on.

\subsection{Survival analysis}

As expected, univariate analysis in the cohort of 326 cases of known histology showed that advanced stage, age $\geq 58$ years of age, residual tumor $\geq 2 \mathrm{~cm}$, grade III/ undifferentiated and serous histology were associated with shorter progression free survival (PFS) and disease-specific overall survival (OS). FR- $\alpha$ expression (low vs. high), was not associated with PFS or OS. In multivariate analysis, advanced stage, serous histology and residual disease were significantly associated with PFS and OS, whereas age, grade and FR- $\alpha$ expression were not (Table 5). In the subgroup of serous carcinomas, advanced stage, residual disease $\geq 2 \mathrm{~cm}$ and high grade were associated with PFS and OS (data not shown). In the subgroup of non-serous tumors, univariate analysis showed associations between stage, age, residual disease and high grade with OS and between stage, residual disease and high grade and PFS. Only advanced stage was prognostic in multivariate analysis (data not shown). The influence of FR- $\alpha$ expression on PFS and OS is shown in survival curves (Fig. $3 a$ and $b$ ).

\section{Discussion}

We analyzed FR- $\alpha$ expression in 361 ovarian cancer tissue samples, of which 326 with known histology. We showed FR- $\alpha$ expression in $81.8 \%$ of serous carcinomas, versus $39.2 \%$ in non-serous carcinomas $(p<0.001)$. FR- $\alpha$ expression did not change significantly after chemotherapy, neither in vital tumor tissue obtained during interval debulking surgery $(p=0.1)$ nor in tumor tissue obtained during surgery for recurrent ovarian cancer $(p=0.5)$.

Table 6 Studies reporting FR- $\alpha$ expression in ovarian cancer

\begin{tabular}{|c|c|c|c|}
\hline Study & No. of patients & Method & FR- $\alpha$ expression \\
\hline Toffoli (1997)[17] & 136 & Cytofluorimetric & $89.7 \%$ \\
\hline Wu (1999)[19] & 23 & In situ hybridization histochemistry & $\begin{array}{l}100 \% \text { serous }(n=10) ; \\
80 \% \text { endometrioid }(n=5) ; \\
0 \% \text { mucinous }(n=6) ; \\
0 \% \text { clear-cell }(n=2)\end{array}$ \\
\hline Bagnoli (2003)[3] & 168 & Immunohistochemistry & $85.1 \%$ non-mucinous ${ }^{\mathrm{a}}$ \\
\hline Parker (2005)[14] & 29 & Radioligand binding assay & $\begin{array}{l}100 \% \text { serous }(n=7) ; \\
100 \% \text { endometrioid }(n=4) ; \\
36 \% \text { mucinous }(n=14)^{\mathrm{b}} ; \\
100 \% \text { metastatic }(n=4)\end{array}$ \\
\hline Kalli (2008)[8] & 186 & Immunohistochemistry & $\begin{array}{l}81.7 \% \text { serous }(n=104) ; \\
66.7 \% \text { endometrioid }(n=39) ; \\
22.2 \% \text { mucinous }(n=9) ; \\
63.3 \% \text { clear-cell }(n=30) ; \\
50 \% \text { mixed }(n=4)\end{array}$ \\
\hline Markert (2008)[12] & 104 & Immunohistochemistry & $97 \%$ non-mucinous ${ }^{\mathrm{c}}$ \\
\hline
\end{tabular}

${ }^{\text {a }}$ Serous, endometrioid and clear-cell carcinoma

${ }^{\mathrm{b}}$ Of 14 mucinous tumors, $36 \%$ showed only weak FR- $\alpha$ expression

${ }^{\mathrm{c}}$ Serous $(n=8)$, serous-papillary $(n=79)$ and papillary carcinoma $(n=17)$ 
Furthermore, FR- $\alpha$ expression in primary ovarian tumors was not associated with survival.

Several studies, summarized in Table 6, report FR- $\alpha$ expression in smaller patient cohorts.

Toffoli et al. reported overall expression of the folate binding protein (FBP) in $89.7 \%$ of 136 patients, with a significant difference in expression between serous and mucinous tumors. FR- $\alpha$ expression was determined using cytofluorimetric analysis [17]. Wu et al. described FR- $\alpha$ expression in gynaecologic malignancies $(n=23)$, measured with in situ hybridization histochemistry. Of 23 malignant ovarian samples, $100 \%$ FR- $\alpha$ expression was seen in serous and endometrioid carcinoma $(n=15)$, versus $0 \%$ expression in mucinous and clear-cell carcinoma $(n=8)$ [19]. Bagnoli et al. analyzed 168 non-mucinous ovarian malignancies, in which an expression rate of $85.1 \%$ was found [3]. Parker et al. compare expression rates in animal tissues and human tissues. Of 29 ovarian tumor patient samples, 100\% expression rates were seen in serous and endometrioid carcinoma and metastatic tissue. Only weak expression was seen in 36\% of mucinous carcinoma [14]. Kalli et al. reported overall expression in $72 \%$ of primary ovarian tumors $(n=186)$, with higher expression in serous carcinoma $(81.7 \%)$ than in other histologic subtypes (59.8\%), with lowest expression in mucinous tumors (22.2\%) [8]. Markert et al. reported 97\% expression in a series of 104 malignant ovarian tumors, but did not specify percentages for histologic subtype [12].

When comparing our data to these studies, FR- $\alpha$ expression in serous carcinoma appears comparable. Remarkable is the high expression rate reported by Markert et al. All studies are uniform in showing low expression rates in mucinous carcinoma, as do we.

The study by Kalli et al. is the only to report FR- $\alpha$ expression in 24 matched samples of both primary and recurrent tumors. No significant difference in expression was found [8]. Our data support these findings. Moreover, by comparing primary surgery specimens to samples from interval debulking surgery as well as to recurrent tumors, we show that chemotherapy has neither a direct, nor a late effect on FR- $\alpha$ expression in remaining vital tumor tissue.

Although our data are in general in line with the reported literature, a remarkable finding is the weak FR- $\alpha$ expression in the majority $(53.3 \%)$ of the primary serous carcinomas. We observed 'moderate' or 'strong' staining in only $28.5 \%$. Numbers are slightly higher in interval debulking specimens and recurrent tumors, but do not exceed 50\%. Little is known regarding the required intensity of FR- $\alpha$ expression for clinical application. Theoretically, lower expression rates may negatively influence the effectiveness of folate-based compounds. Since no data are available to confirm whether low expression implicates less effective tumor-targeting, further studies are warranted to elucidate this question. From the present study, we conclude that the strength of FR- $\alpha$ expression may be a relevant factor to be specifically addressed in future studies.

In summary, this study confirms previously found FR- $\alpha$ expression rates of $\sim 82 \%$ in serous ovarian carcinoma, although strong expression was seen in a smaller proportion of tumors than earlier reported. FR- $\alpha$ was not associated with progression free survival, nor with disease-specific overall survival. Furthermore, in this limited series, we show that chemotherapy does not significantly alter FR- $\alpha$ expression in vital residual tumor tissue, thus strengthening the rationale for FR- $\alpha$ targeted diagnostic agents and drugs.

Acknowledgements The authors wish to thank mrs. T. van der Sluis for immunohistochemical staining; and Dr. R. Vermeij for help with data management and statistical analyses. The authors declare no conflict of interest.

Open Access This article is distributed under the terms of the Creative Commons Attribution Noncommercial License which permits any noncommercial use, distribution, and reproduction in any medium, provided the original author(s) and source are credited.

\section{References}

1. A.C. Antony, Folate receptors. Annu. Rev. Nutr. 16, 501-521 (1996)

2. D.K. Armstrong, A. Bicher, R.L. Coleman, D.G. Gibbon, D. Glenn, L. Old, N.N. Senzer, A. Schneeweiss, R.H. Verheijen, A.J. White, S. Weil, Exploratory phase II efficacy study of MORAb003, a monoclonal antibody against folate receptor alpha, in platinum-sensitive ovarian cancer in first relapse. J. Clin. Oncol. 26, 5500 (2008) (Meeting Abstracts)

3. M. Bagnoli, S. Canevari, M. Figini, D. Mezzanzanica, F. Raspagliesi, A. Tomassetti, S. Miotti, A step further in understanding the biology of the folate receptor in ovarian carcinoma. Gynecol. Oncol. 88, S140-S144 (2003)

4. J.L. Benedet, H. Bender, H. Jones III, H.Y. Ngan, S. Pecorelli, FIGO staging classifications and clinical practice guidelines in the management of gynecologic cancers. FIGO Committee on Gynecologic Oncology. Int. J. Gynaecol. Obstet. 70, 209-262 (2000)

5. P. de Graeff, J. Hall, A.P. Crijns, G.H. de Bock, J. Paul, K.A. Oien, K.A. ten Hoor, S. de Jong, H. Hollema, J.M. Bartlett, R. Brown, A.G. van der Zee, Factors influencing p53 expression in ovarian cancer as a biomarker of clinical outcome in multicentre studies. Br. J. Cancer 95, 627-633 (2006)

6. W. Ebel, E.L. Routhier, B. Foley, S. Jacob, J.M. McDonough, R. K. Patel, H.A. Turchin, Q. Chao, J.B. Kline, L.J. Old, M.D. Phillips, N.C. Nicolaides, P.M. Sass, L. Grasso, Preclinical evaluation of MORAb-003, a humanized monoclonal antibody antagonizing folate receptor-alpha. Cancer Immun. 7, 6 (2007)

7. A. Jemal, R. Siegel, E. Ward, Y. Hao, J. Xu, T. Murray, M.J. Thun, Cancer statistics, 2008. CA Cancer J. Clin. 58, 71-96 (2008)

8. K.R. Kalli, A.L. Oberg, G.L. Keeney, T.J. Christianson, P.S. Low, K. L. Knutson, L.C. Hartmann, Folate receptor alpha as a tumor target in epithelial ovarian cancer. Gynecol. Oncol. 108, 619-626 (2008)

9. C.P. Leamon, P.S. Low, Delivery of macromolecules into living cells: a method that exploits folate receptor endocytosis. Proc. Natl. Acad. Sci. U. S. A. 88, 5572-5576 (1991)

10. C.P. Leamon, M.A. Parker, I.R. Vlahov, L.C. Xu, J.A. Reddy, M. Vetzel, N. Douglas, Synthesis and biological evaluation of EC20: a new folate-derived, $(99 \mathrm{~m}) \mathrm{Tc}-$ based radiopharmaceutical. Bioconjug. Chem. 13, 1200-1210 (2002) 
11. P.S. Low, W.A. Henne, D.D. Doorneweerd, Discovery and development of folic-acid-based receptor targeting for imaging and therapy of cancer and inflammatory diseases. Acc. Chem. Res. 41, 120-129 (2008)

12. S. Markert, S. Lassmann, B. Gabriel, M. Klar, M. Werner, G. Gitsch, F. Kratz, A. Hasenburg, Alpha-folate receptor expression in epithelial ovarian carcinoma and non-neoplastic ovarian tissue. Anticancer. Res. 28, 3567-3572 (2008)

13. C.J. Mathias, S. Wang, D.J. Waters, J.J. Turek, P.S. Low, M.A. Green, Indium-111-DTPA-folate as a potential folate-receptortargeted radiopharmaceutical. J. Nucl. Med. 39, 1579-1585 (1998)

14. N. Parker, M.J. Turk, E. Westrick, J.D. Lewis, P.S. Low, C.P. Leamon, Folate receptor expression in carcinomas and normal tissues determined by a quantitative radioligand binding assay. Anal. Biochem. 338, 284-293 (2005)

15. B.A. Siegel, F. Dehdashti, D.G. Mutch, D.A. Podoloff, R. Wendt, G.P. Sutton, R.W. Burt, P.R. Ellis, C.J. Mathias, M.A. Green, D.M.
Gershenson, Evaluation of 111In-DTPA-folate as a receptortargeted diagnostic agent for ovarian cancer: initial clinical results. J. Nucl. Med. 44, 700-707 (2003)

16. W.A. Spannuth, A.K. Sood, R.L. Coleman, Farletuzumab in epithelial ovarian carcinoma. Expert. Opin. Biol. Ther. 10, 431437 (2010)

17. G. Toffoli, C. Cernigoi, A. Russo, A. Gallo, M. Bagnoli, M. Boiocchi, Overexpression of folate binding protein in ovarian cancers. Int. J. Cancer 74, 193-198 (1997)

18. W.E. Winter III, G.L. Maxwell, C. Tian, M.J. Sundborg, G.S. Rose, P.G. Rose, S.C. Rubin, F. Muggia, W.P. McGuire, Tumor residual after surgical cytoreduction in prediction of clinical outcome in stage IV epithelial ovarian cancer: a Gynecologic Oncology Group Study. J. Clin. Oncol. 26, 83-89 (2008)

19. M. Wu, W. Gunning, M. Ratnam, Expression of folate receptor type alpha in relation to cell type, malignancy, and differentiation in ovary, uterus, and cervix. Cancer Epidemiol. Biomark. Prev. 8, $775-782$ (1999) 